\title{
Analysis of Emergency Medical Response Service in Peshawar through Simulation
}

\author{
RASHID NAWAZ*, SHAHID MAQSOOD*, AND ABDUR REHMAN BABAR*
}

RECEIVED ON 11.04.2018 ACCEPTED ON 17.08.2018

\begin{abstract}
EMRS (Emergency Medical Response Service) is the public safety system that is responsible for the initial first aid and transportation of the patient to the hospital. Providing a timely response to any emergency situation is of critical nature and needs to be addressed in the shortest possible time. Decreasing the response to an emergency site and timely pre-hospitalization care location identification and number of emergency response personnel and vehicles are some of the critical elements of EMRS. In this research, a probabilistic model is developed which incorporates the probabilistic response to any emergency situation. The developed model was applied to an actual scenario of the EMRS in the city of Peshawar, Pakistan. The EMRS has 7 locations covering 7 different regions of the city covering more than 1200 square kilometers area. The main purpose of the study is to measure the quality of EMRS on the basis of response time and queue. The study has identified that station 1 and 2 have the highest utilization; 58\% each, while station 7 has the lowest utilization at $13.7 \%$. Since the emergency care at the site of incidence is one of the primary responsibilities of the public safety organizations so this study also discusses the average instantaneous utilization of EMRS resources for that region.
\end{abstract}

Key Words: Emergency Medical Response Service, Simulation, ARENA, Locations.

\section{INTRODUCTION}

$\mathrm{T}$

he provision of effective and time dependent emergency and ambulance response service is a problem that is being faced by almost all the major cities around the world. The EMRS technicians are first at the site of incident to provide quick and adequate stabilization to sick and injured patients. The purpose of emergency medical response service is to respond promptly to the emergency calls by providing first aid services and shifting patients, if required, to the emergency care unit of the nearest hospital [1]. Indeed, proper pre-hospital care can reduce casualty and morbidity considerably [2]. Previous literature shows that the survival rate for non-traumatic cardiac arrest patients can be improved significantly through an onsite appropriate medical care [2-7]. A study by [8] concludes that $33 \%$ reduction in the probability of death can be achieved if the emergency medical response time is reduced by 10 minutes (25-15 minutes), in road side accidents.

Authors E-Mail: (rnawaz@uetpeshawar.edu.pk,smaqsood@uetpeshawar.edu.pk, abdurrehman@uetpeshawar.edu.pk)

* Department of Industrial Engineering, University of Engineering \& Technology, Peshawar, Pakistan. 
EMRS providers are faced with the problem of locating the site of incident, the nature of emergency and the current location of the ambulance before an ambulance or other emergency vehicle could be dispatched, and all this has to be done in the least possible time [9]. In addition, emergency service providers are also confronted with the problem of how and where to locate vehicles in order to cover potential future demand effectively. Ambulances should be located at selected locations such that in case of an emergency the patients can be rescued in a time-efficient manner. Usually a patient is assumed to be served by an ambulance if (s)he can be reached by a within a certain time limit [10]. Most studies on ambulance deployment or location problems are based on a minimal covering model [11-12], which minimize the total number of ambulances required while covering all demand points, and a maximal covering model [13] that tries to maximize the total demand covered.

\section{GOALS AND OBJECTIVES}

The goal of this research is to determine the utilization of current available resources of EMRS Peshawar. In any emergency medical response service, it is important to know the current utilization of the system (i.e. whether the EMRS system has enough resources) to efficiently respond to all the emergency calls and serve the location as per requirements.

Previously studies conducted for EMRS in Pakistan were focused on ambulance response time and financial factor in using private EMRS. However, this research attempts to analyze the EMRS system in Peshawar on the basis of utilization of resources by simulating it in ARENA. The main research contributions of this paper are:
- $\quad$ To simulate and analyze the data of EMRS Peshawar to identify the current utilization of EMS system, which will aid in determining whether it can handle all the emergency calls or not.

- To analyze the utilization of resources of each of 7 stations of EMRS.

- To find the availability of ambulances for emergency in each of 7 stations.

- $\quad$ To analyze the load on each station separately.

- To find out capacity of system, whether it can meet the current requirement or not.

\subsection{Emergency Medical Services Operation Procedure}

The process of intervention of an EMRS to an emergency site includes the following four steps: (1) incident detection and reporting to the EMRS control room, (2) call screening, (3) vehicle dispatching, and (4) actual intervention by paramedics [14]. The decision for dispatching the ambulance are to be made quickly by the emergency call operators for each incoming call [1] .

Vehicle dispatching is one of the several critical decisions made by emergency control room managers. The emergency calls are forwarded to one of the seven EMRS stations (nearest one to the site of incident) for dispatching the ambulance. The other critical decision made by the emergency control room managers is the screening process to judge how severe the incident is and its degree of required urgency, so to make a decision for total ambulances required. Once the ambulance is dispatched, the control room dispatcher is made available to take another call of emergency. The process flow is shown in Fig. 1. 


\subsection{Decisions Needed to Address the EMRS Operations}

The decisions that affect the EMRS operations can be classified into three categories: long term, medium term, and short term. The long term decisions are the ones that determine the service levels performance that needs to be achieved along with other criteria such as the economic impact, human skills requirement, areas or population that needs to be covered in future. The medium term decision usually consists of determining the EMRS stations that needs to be opened among the EMRS stations designated in the long term decisions, the number of emergency staff, ambulances, and their deployment to various stations on the basis of demand in that specific area and their levels of utilization. The short term decisions are usually the operational requirements, such as the number of EMRS

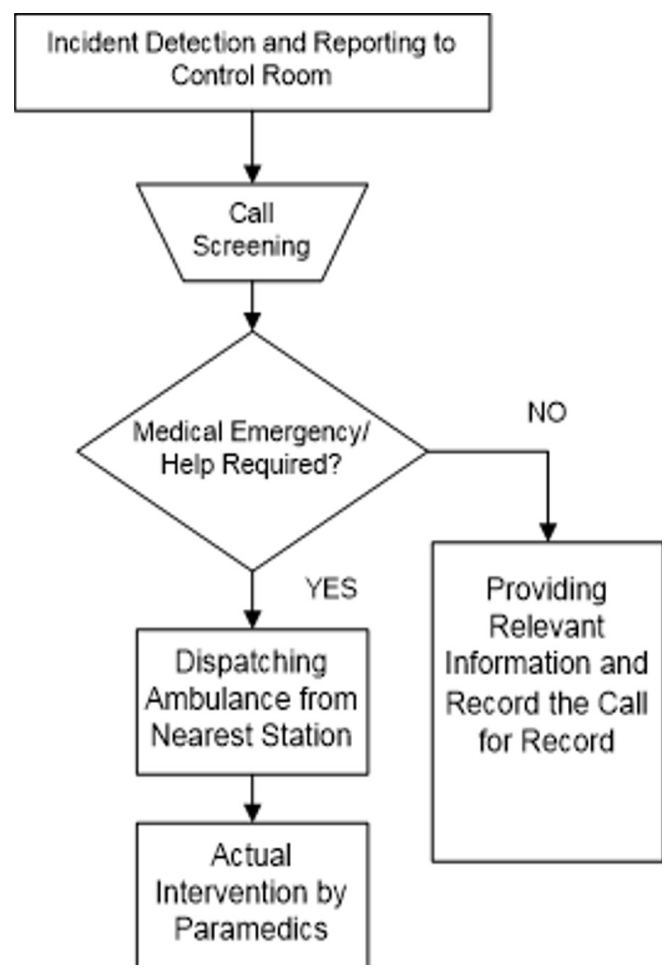

FIG. 1. FLOW CHART FOR THE CHAIN OF EVENTS LEADING TO INTERVENTION OF EMRS TO THE SITE OF INCIDENCE technicians and the number of ambulances to be dispatched at different types of emergencies, selection of appropriate hospitals at different locations that reduces the patient transportation time.

Simulation is now widely used in a broad spectrum of fields including but not limited to healthcare [15]. Because of the stochastic and dynamic nature of health care problems, discrete event simulation is used. Within the health care system, simulation is now been increasingly used in areas such as hospital bed capacity planning [16], emergency room settings [17], and patient flow and their waiting times. The simulation also addresses the issues such as the expense of maintaining the EMRS stations in places that will minimize the travel time to the site of incidence, improve the chances of patient survival, and keep the recurring cost within limits [18-19].

In Peshawar, KPK (Khyber Pakhtunkhwa) there is a greater need to re-assess the present EMRS stations that are located in and around the city, in the current prevailing situation, where the population has more than doubled since the last census in 1998.

According to last Census data [20], Peshawar was home to $20,26,851$ people, and was spread over an area of 1257 square kilometers, with a population density of 1612.5 persons per square kilometer. The average population growth rate for the province in urban localities during the time period 1981-1998 was 3.51\% (Population Census Organization, Government of Pakistan), it is assumed that the same rate of population growth has continued from 1998-2017 thus making population of Peshawar to be approximately 4438431 in the year 2017. 
The mission of the EMRS is "Timely, Professional and Scientific, response to any Emergency" [21]. This objective can be achieved by providing the proper medical care on time at the location of the incidents. Hence, the success of EMRS system can be measured by the rapid and appropriate response provided at the site of the incident [22]. The EMRS has divided the city into seven zones, each zone being covered by one EMRS station. Each EMRS station has 2 ambulances to cater to the need of the region in case of an incident. The EMRS is open 24 hours a day with no holiday, and operates in 3 shifts of 8 hours each.

The ARENA simulation software was used to imitate the actual scenario. The purpose is to identify the points that might become bottlenecks in the speedy response to any emergency call. The EMRS models are divided into two categories: deterministic or stochastic, Deterministic models are attractive because they suggest the "best" decision given a set of constraints and quantifiable performance measures [22].

\section{DATA COLLECTION}

Data was collected from the Rescue-1122 (EMRS in Peshawar) for the emergency calls for the period of 90 days that were received during January $1^{\text {st }}, 2017$ and March $31^{\text {st }}, 2017$, Table 1 shows data in 24-hour time format.

The calls are divided into 24-hour time period and the probability distribution was determined to simulate the calls arrivals time.

This data was analyzed to determine the percentage of calls that were forwarded to different EMRS stations around the city. Total number of emergency calls arrived on each EMRS station is calculated and their percentage is displayed in Table 2. The percentage shows the load on each station.

\subsection{Data Analysis}

The call arrivals were plotted on histogram showing the average number of call arrivals at each hour in the 24hour period for the 90 days (Fig. 2).

The data was then fitted into a theoretical distribution. Input analyzer, a module of Arena software is used to fit the theoretical distribution on data. The theoretical distribution shows the probability distribution, which the data is following, along with its parameters (Fig. 3). Then these parameters were put in the simulation model.

The data showed the Beta distribution with parameters of $\alpha_{1}=1.1075$ and $\alpha_{2}=0.67136$ for emergency calls arrival.

In addition, to check the reliability of the data, Kalmogorov Smirnov and Chi Square tests were performed.

The chi Square $\chi^{2}$ statistics was calculated using the Equation (1).

$\chi^{2}=\sum_{i=1}^{k} \frac{(f o i-f e i)^{2}}{f e i}$

Where $K$ is Number of Classes or intervals $f_{o i}$ is expected frequency for the class or interval $i$

$f_{e i \text { is }}$ Expected frequency for the class or the interval $i$ predicted by the theoretical distribution.

For the Beta distribution the $\chi^{2}=0.58332$

The Kolmogorov Smirnov test was also performed for goodness of fit using the Equation (2).

$$
F_{01}=\frac{\sum_{i=1}^{i} f o i}{\sum_{j=1}^{i} f_{o i}}
$$


Analysis of Emergency Medical Response Service in Peshawar through Simulation

TABLE 1. CALL ARRIVALS IN 24 HOUR TIME PERIOD

\begin{tabular}{|c|c|c|}
\hline Time Range & Average Calls Received/Hour & Total Number of Calls Received in 90 Days \\
\hline 0:00-0:59 & 0.72 & 65 \\
\hline 1:00-1:59 & 0.52 & 47 \\
\hline 2:00-2:59 & 0.38 & 34 \\
\hline 3:00-3:59 & 0.40 & 36 \\
\hline 4:00-4:59 & 0.30 & 27 \\
\hline $5: 00-5: 59$ & 0.18 & 16 \\
\hline $6: 00-6: 59$ & 0.32 & 29 \\
\hline 7:00-7:59 & 0.42 & 38 \\
\hline $8: 00-8: 59$ & 0.70 & 63 \\
\hline 9:00-9:59 & 0.60 & 54 \\
\hline 10:00-10:59 & 0.81 & 73 \\
\hline 11:00-11:59 & 0.97 & 87 \\
\hline $12: 00-12: 59$ & 0.94 & 85 \\
\hline 13:00-13:59 & 0.93 & 84 \\
\hline 14:00-14:59 & 0.70 & 63 \\
\hline 15:00-15:59 & 0.84 & 76 \\
\hline 16:00-16:59 & 0.86 & 77 \\
\hline 17:00-17:59 & 0.79 & 71 \\
\hline 18:00-18:59 & 0.81 & 73 \\
\hline 19:00-19:59 & 1.00 & 90 \\
\hline 20:00-20:59 & 0.98 & 88 \\
\hline 21:00-21:59 & 0.79 & 71 \\
\hline $22: 00-22: 59$ & 0.93 & 84 \\
\hline $23: 00-23: 59$ & 0.77 & 69 \\
\hline
\end{tabular}

TABLE 2. PERCENTAGE OF CALLS PER STATION

\begin{tabular}{|c|c|c|c|}
\hline EMRS Station & Name/Location & Frequency & $\begin{array}{c}\text { Calls Received/Station } \\
(\%)\end{array}$ \\
\hline 11 & Civil Defence Office, GT Road, Near Daewoo Bus Stand & 389 & 25.06 \\
\hline 22 & Eid Gah Near Faqirabad Police Station, Charsadda Road & 401 & 25.84 \\
\hline 33 & City Fire Brigade, Kohati Gate Peshawar & 401 & 12.89 \\
\hline 44 & City Hospital, Kohat Road Peshawar & 200 & 11.08 \\
\hline 55 & Tariq Road, Near Press Club Peshawar & 172 & 9.86 \\
\hline 66 & Town-III, TMA Building, University Road Peshawar & 153 & 9.41 \\
\hline 77 & Back side of Hayatabad Medical Complex, Hayatabad Peshawar & 146 & 5.86 \\
\hline
\end{tabular}

Mehran University Research Journal of Engineering \& Technology, Volume 38, No. 4, October, 2019 [p-ISSN: 0254-7821, e-ISSN: 2413-7219] 
For the Beta Distribution the Kolmogorov Smirnov Statistic $=0.12724$.

The ambulance response time data was provided by the EMRS control room. Data was provided for each station regarding how much time an ambulance take to reach the emergency site after dispatching from EMRS station. The data was plotted in a histogram and probability distribution was checked by input analyzer. The result was triangular distribution (Fig. 4) for the ambulance response time (in minutes) with following parameters, $a=50$ minutes, $m=60$ minutes,$b=70$ minutes

$\mathrm{a}$ is Minimum Time, $\mathrm{m}$ is Most Likely Time, $\mathrm{b}$ is Maximum Time

The data for operator time; the time during which the EMRS control room operator gathers the required information about the site and nature of emergency and making a decision to forward the call to the EMRS station of that region, is taken from the EMRS control room. The data provided was in minutes.

$\mathrm{a}=0.50$ minutes, $\mathrm{m}=1$ minute, $\mathrm{b}=1.5$ minutes

Average Calls Received per Hour

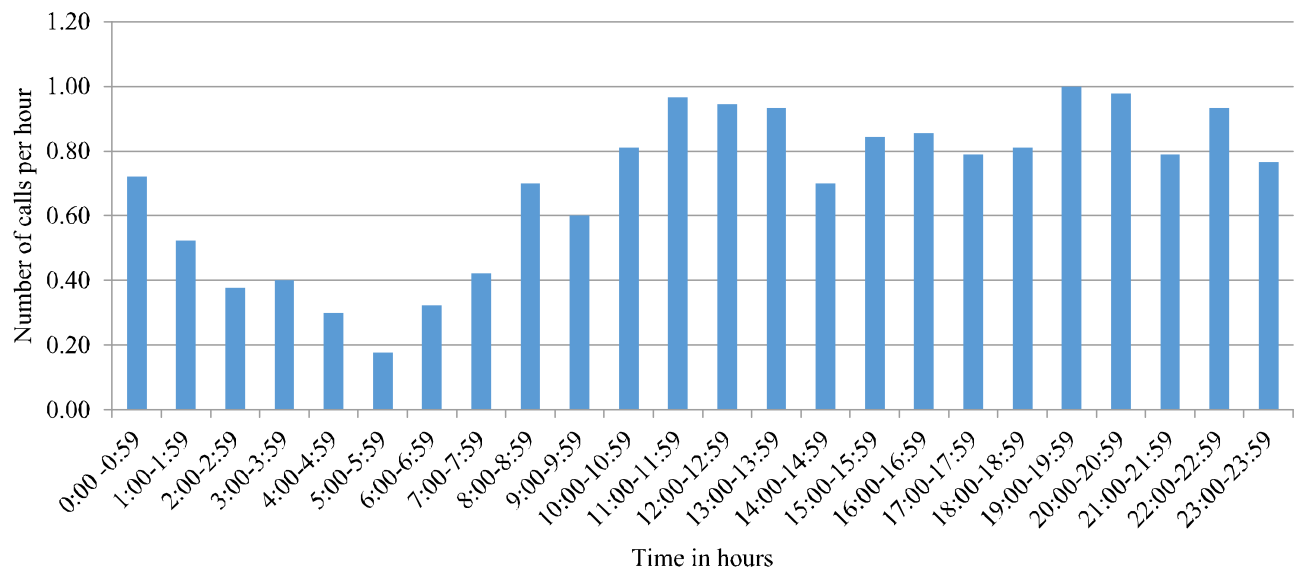

FIG. 2. HISTOGRAM FOR THE CALLS ARRIVAL

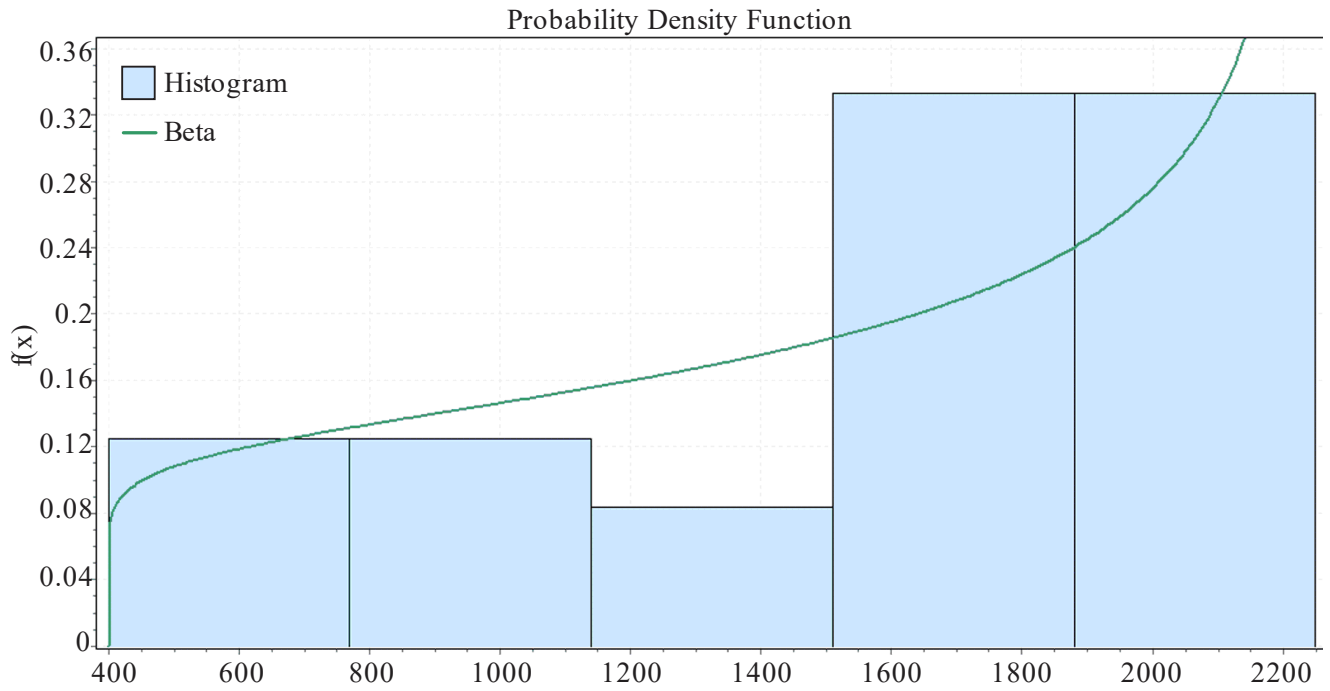

FIG. 3. THEORETICAL PROBABILITY DISTRIBUTION FOR THE CALLS ARRIVAL 


\section{EMRS SIMULATION MODEL}

The simulation model was developed in ARENA. First of all, the calls arrival was created for incoming calls reporting incident or emergency. If the operator line is available then it will receive the call otherwise the call will be rejected. The beta distribution was used for the inter-arrival call times and triangular distribution was deployed for operator call duration (the process of selecting the distributions is already explained before). This process in simulation software (Arena) is shown in Fig. 5.

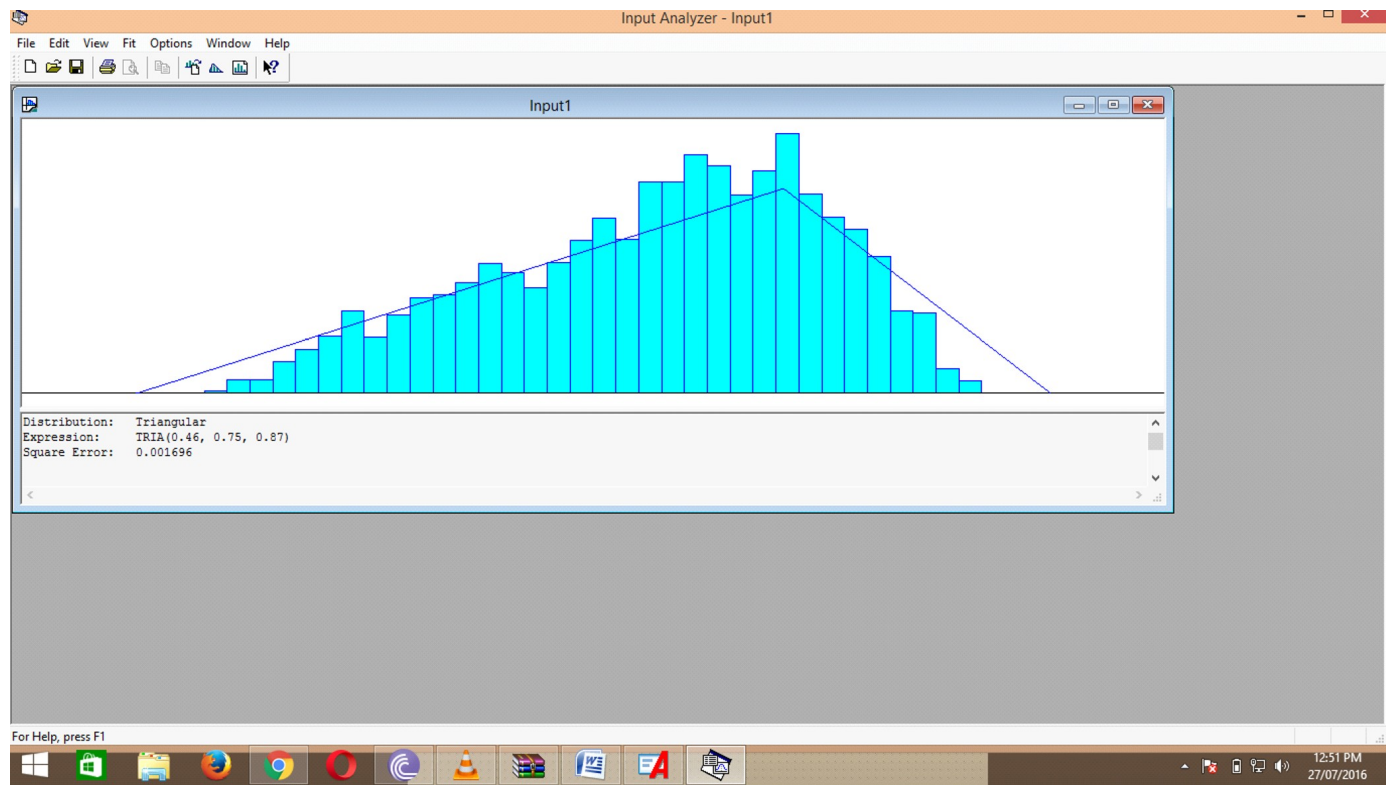

FIG. 4. TRIANGULAR DISTRIBUTION FOR AMBULANCE RESPONSE

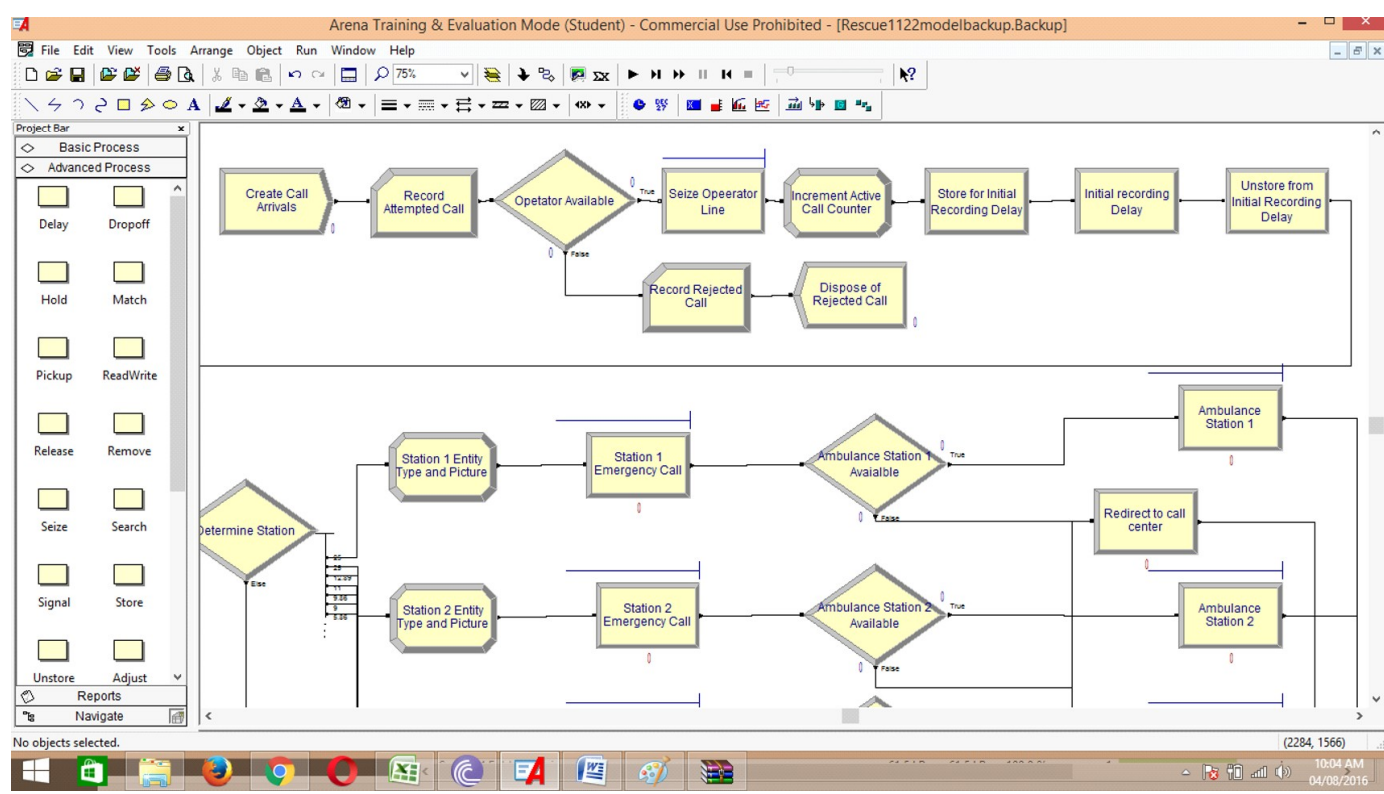

FIG. 5. SIMULATION MODEL FOR INCOMING CALLS

Mehran University Research Journal of Engineering \& Technology, Volume 38, No. 4, October, 2019 [p-ISSN: 0254-7821, e-ISSN: 2413-7219] 
After listening to the call, the operator direct the call to the corresponding EMRS station. For example, if the call is from the area of EMRS station 11, the call is forwarded to that station. The calls were forwarded to their respective stations with the same percentage as already determined in Table 2, from the actual data.

The respective station after receiving the call from control room, checks whether ambulance is available for the emergency response or not. If the ambulance is available then it will be dispatched to the emergency location otherwise the call is forwarded to the main control room for alternative arrangement. The process of simulation is shown in Fig. 6.

The time consumed by ambulance to reach to the site of incident and reporting back to the base station is triangularly distributed. This model has a replication length of 10000 hours, with a 30 hours warm up time. The model was run for 83 replications.

\subsection{Output Analysis}

The model was run for 10000 hours with total 83 replications. The results show that the average number of calls served in each replication was 39858 . The simulation model showed the results for both call operator and ambulance for each station in term of waiting time in queue, number of calls waiting for service and utilization.

The waiting time in queue for each ambulance station, number of calls waiting for being served and the utilization of each station is shown in Tables 3-7.

In Table 3 the values for waiting time are relatively higher for the EMRS stations 1 and 2 for an emergency call to be served by an ambulance i.e it takes 18.6 minutes to serve an emergency call on both the stations. While on rest of the stations, on average, the ambulances are available within 4 minutes when an emergency call is recieved.

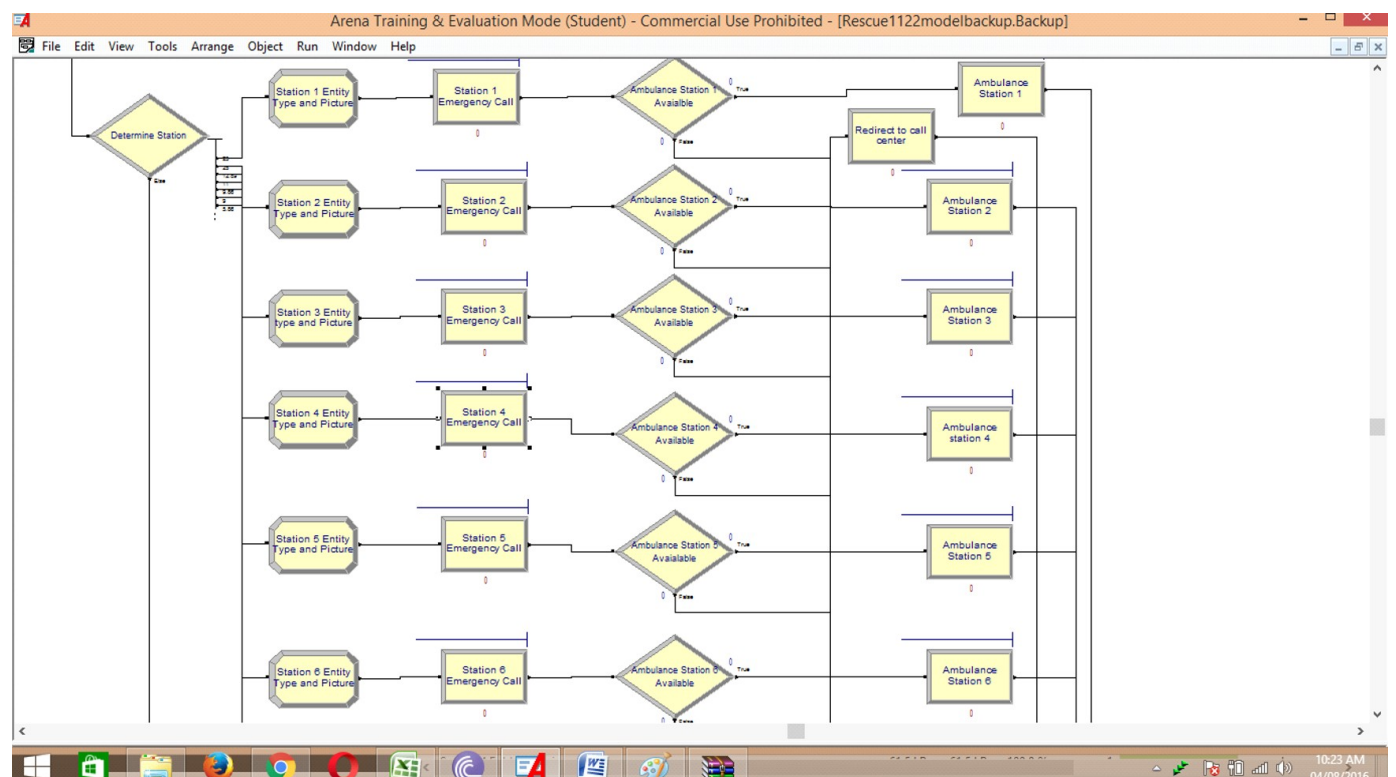

FIG. 6. SIMULATION MODEL FOR DISPATCHING OF AMBULANCE FROM EACH STATION

Mehran University Research Journal of Engineering \& Technology, Volume 38, No. 4, October, 2019 [p-ISSN: 0254-7821, e-ISSN: 2413-7219] 
Table 4 shows the total number of emergency calls waiting in queue for ambulance availability. On the EMRS station 1 and 2 the average is relatively higher which is 0.311 minutes for each station. Still the waiting time for each call to be served by ambulance is less than a minute.
The Table 5 shows that there is highest utilization of ambulance at station 1 and 2 which are 58.26 and $58.27 \%$ respectively, while rest all the EMRS stations have very low utilization. Station 7 has the lowest utilization which is $13.71 \%$.

TABLE 3. WAITING TIME OF EACH EMERGENCY SITUATION BEING SERVED BY AN AMBULANCE

\begin{tabular}{|c|c|c|c|}
\hline EMRS Station & $\begin{array}{c}\text { Minimum Time } \\
\text { (Minutes) }\end{array}$ & $\begin{array}{c}\text { Maximum Time } \\
\text { (Minutes) }\end{array}$ & $\begin{array}{c}\text { Average Time } \\
\text { (Minutes) }\end{array}$ \\
\hline 1 & 16.805 & 21.020 & 18.680 \\
\hline 2 & 16.858 & 20.691 & 18.687 \\
\hline 3 & 3.349 & 4.439 & 3.845 \\
\hline 4 & 2.218 & 3.296 & 2.762 \\
\hline 5 & 1.726 & 2.730 & 1.863 \\
\hline 6 & 1.447 & 2.409 & 0.789 \\
\hline 7 & 0.525 & 1.157 & 2.217 \\
\hline
\end{tabular}

TABLE 4. NUMBER OF EMERGENCY CALLS WAITING FOR BEING SERVED BY AN AMBULANCE

\begin{tabular}{|c|c|c|c|}
\hline EMRS Station & $\begin{array}{c}\text { Minimum } \\
(\%)\end{array}$ & $\begin{array}{c}\text { Maximum } \\
(\%)\end{array}$ & $\begin{array}{c}\text { Average } \\
(\%)\end{array}$ \\
\hline 1 & 0.278 & 0.36 & 0.311 \\
\hline 2 & 0.275 & 0.351 & 0.311 \\
\hline 3 & 0.028 & 0.038 & 0.033 \\
\hline 4 & 0.016 & 0.024 & 0.02 \\
\hline 5 & 0.011 & 0.017 & 0.011 \\
\hline 6 & 0.008 & 0.014 & 0.003 \\
\hline 7 & 0.0001 & 0.004 & 0.014 \\
\hline
\end{tabular}

TABLE 5. UTILIZATION OF EACH EMRS STATION IN SERVING EMERGENCY SITUATION

\begin{tabular}{|c|c|c|c|}
\hline EMRS Station & $\begin{array}{c}\text { Minimum } \\
(\%)\end{array}$ & $\begin{array}{c}\text { Maximum } \\
(\%)\end{array}$ & $\begin{array}{c}\text { Average } \\
(\%)\end{array}$ \\
\hline 1 & 57.11 & 59.99 & 58.26 \\
\hline 2 & 56.80 & 59.79 & 58.27 \\
\hline 3 & 28.75 & 30.84 & 30.07 \\
\hline 4 & 24,59 & 26.24 & 25.63 \\
\hline 5 & 21.69 & 23.96 & 21.05 \\
\hline 6 & 19.99 & 22.03 & 13.71 \\
\hline 7
\end{tabular}

Mehran University Research Journal of Engineering \& Technology, Volume 38, No. 4, October, 2019 [p-ISSN: 0254-7821, e-ISSN: 2413-7219] 
The call waiting time and the operator utilization that recieves the call for each EMRS station is shown in the Tables 6-7.

The waiting time for each call being served by operator is shown in minutes. Table 6 shows that the highest average waiting time is at EMRS station 1 and 2 which is 0.008 minutes for each while rest all the stations have less waiting time. The waiting time for emergency call is very less which shows that when call arrives the operator is available to pick the call.

Table 7 shows the utilization of call opartor at each EMRS station. The results shows that the maximum utilization of operator is at station 1 and 2 which is $1.6 \%$ each while the rest all the operator on other EMRS stations have very lower utilization. The lowest utilization is of operator at EMRS station 7 whose utilization is only $0.3 \%$. This shows that most of the time the operator are idle and are available to pick and respond the emergency calls.

\section{CONCLUSIONS}

In this study, we found out that all the seven EMRS are under-utilized and there is none calls waiting to be served. This study reveals that although the population and the area to cover is too large to be served by the seven EMRS

TABLE 6. WAITING TIME OF EMERGENCY CALL TO SERVE ON EACH EMERGENCY STATION

\begin{tabular}{|c|c|c|c|}
\hline EMRS Station/Emergency Call & $\begin{array}{c}\text { Minimum Time } \\
\text { (Minutes) }\end{array}$ & $\begin{array}{c}\text { Maximum Time } \\
(\text { Minutes })\end{array}$ & $\begin{array}{c}\text { Average Time } \\
\text { (Minutes) }\end{array}$ \\
\hline 1 & 0.006 & 0.01 & 0.008 \\
\hline 2 & 0.007 & 0.01 & 0.008 \\
\hline 3 & 0.002 & 0.007 & 0.004 \\
\hline 4 & 0.002 & 0.005 & 0.003 \\
\hline 5 & 0.001 & 0.005 & 0.003 \\
\hline 6 & 0.001 & 0.004 & 0.002 \\
\hline 7 & 0.000 & 0.004 & 0.003 \\
\hline
\end{tabular}

TABLE 7. WAITING TIME OF EMERGENCY CALL TO SERVE ON EACH EMERGENCY STATION

\begin{tabular}{|c|c|c|c|}
\hline Station/Operator & $\begin{array}{c}\text { Minimum } \\
(\%)\end{array}$ & $\begin{array}{c}\text { Maximum } \\
(\%)\end{array}$ & $\begin{array}{c}\text { Average } \\
(\%)\end{array}$ \\
\hline 1 & 1.6 & 1.7 & 1.6 \\
\hline 2 & 1.6 & 1.7 & 0.8 \\
\hline 3 & 0.8 & 0.8 & 0.7 \\
\hline 4 & 0.7 & 0.7 & 0.6 \\
\hline 5 & 0.6 & 0.6 & 0.6 \\
\hline 6 & 0.6 & 0.6 & 0.3 \\
\hline 7 & 0.3 & 0.4 & 0.6 \\
\hline
\end{tabular}

Mehran University Research Journal of Engineering \& Technology, Volume 38, No. 4, October, 2019 [p-ISSN: 0254-7821, e-ISSN: 2413-7219] 
stations, however, the number of emergency calls generated are too low that ultimately results in no queue being build up. There seem to be some problem in EMRS stations 1 and 2, that is the waiting time for an emergency call to be served by and ambulance is relatively greater, 16 minutes, which should be minimized. Although the utilization of EMRS stations 1 and 2 is only $58 \%$ for each, while the number of calls to be waiting for ambulance service is less is 0.27 call for each station. As far as the call operator is concerned, enough numbers of call operators are available to receive the emergency calls as the maximum waiting time for each call to be served by the operator is only 0.008 minutes for EMRS station 1 and 2 while the maximum utilization is for station 1 and 2 which is $1.6 \%$ for each. This shows that enough number of operators are available to attend the emergency call.

The low utilization of resources suggests that an awareness campaign be initiated among the local population that will increase the utilization of the stations.

\section{FUTURE RESEARCH}

It is suggested that further studies may be conducted while considering the variable speed of ambulances during rush and non-rush hours, actual population according to census with identification of thickly and thinly populated areas of the city.

This research study will help the community in several ways; optimization of the travel distance will reduce the response timer resulting in lives saves, it will also optimize the number of ambulances needed at each zone thus help in curtailing the EMRS stations budget and the study could be expanded and used in future in other towns as well with some minor modifications.

\section{ACKNOWLEDGEMENTS}

The Rescue-1122 has provided the data for analysis and research, and University of Engineering \& Technology, Peshawar, Pakistan, has provided this research project from endowment fund of the university.

\section{REFERENCES}

[1] Aboueljinane, L., Sahin, E., and Jemai, Z., "A Review on Simulation Models Applied to Emergency Medical Service Operations", Computers \& Industrial Engineering, Volume 66, No. 4, pp. 734-750, 2013.

[2] Su, S., and Shih, C.-L., "Modeling an Emergency Medical Services System Using Computer Simulation", International Journal of Medical Informatics, Volume 72, No. 1-3, pp. 57-72, 2003.

[3] Urban, N., Bergner, L., and Eisenberg, M.S., "The Costs of a Suburban Paramedic Program in Reducing Deaths Due to Cardiac Arrest", Medical Care, Volume 19, No. 4, pp. 379-392, 1981.

[4] Riediger, G., and Fleischmann-Sperber, T., "Efficiency and Cost-Effectiveness of Advanced EMS in West Germany", The American Journal of Emergency Medicine, Volume 8, No. 1, pp. 76-80, 1990.

[5] Hallstrom, A., Eisenberg, M.S., and Bergner, L., "Modeling the Effectiveness and Cost-Effectiveness of an Emergency Service System", Social Science \& Medicine. Part-C: Medical Economics, Volume 15, No. 1, pp. 13-17, 1981.

[6] Nichol, G, Detsky, A.S., Stiell, I.G., O’Rourke, K., Wells, G., and Laupacis, A., "Effectiveness of Emergency Medical Services for Victims of Out-of-Hospital Cardiac Arrest: A Metaanalysis", Annals of Emergency Medicine, Volume 27, No. 6, pp. 700-710, 1996.

[7] White, R.D., Asplin, B.R., Bugliosi, T.F., and Hankins, D.G., "High Discharge Survival Rate After Out-ofHospital Ventricular Fibrillation with Rapid Defibrillation by Police and Paramedics", Annals of Emergency Medicine, Volume 28, No. 5, pp. 480-485, 1996. 
[8] Sánchez-Mangas, R., García-Ferrrer, A., de Juan, A., and Arroyo, A.M., "The Probability of Death in Road Traffic Accidents: How Important is a Quick Medical Response?", Accident Analysis \& Prevention, Volume 42, No. 4, pp. 1048-1056, 2010.

[9] Schmid, V., "Solving the Dynamic Ambulance Relocation and Dispatching Problem Using Approximate Dynamic Programming", European Journal of Operational Research, Volume 219, No. 3, pp. 611-621, 2012.

[10] Verena Schmid, K.F.D., "Ambulance Location and Relocation Problems with Time-Dependent Travel Times", European Journal of Operational Research, Volume 207, No. 3, pp. 1293-1303, 2010

[11] Constantine Toregas, R.S., ReVelle, C., and Bergman, L., The Location of Emergency Service Facilities", Operations Research, Volume 19, No. 6, pp. 1363-1373, 1971.

[12] Zhen, L., Wang, K., Hu, H., and Chang, D., “A Simulation Optimization Framework for Ambulance Deployment and Relocation Problems”, Computers \& Industrial Engineering, Volume 72, pp. 12-23, 2014.

[13] Church, R., and ReVelle, C., "The Maximal Covering Location Problem", Regional Science Association, Volume 32, No. 1, pp. 101-118, 1974.

[14] Brotcorne, L., Laporte, G., and Semet, F., “Ambulance Location and Relocation Models", European Journal of Operational Research, Volume 147, No. 3, pp. 451-463, 2003.
[15] Negahban, A., and Smith, J.S., "Simulation for Manufacturing System Design and Operation: Literature Review and Analysis", Journal of Manufacturing Systems, Volume 33, No. 2, pp. 241-261, 2014.

[16] Holm, L.B., Lurås, H., and Dahl, F.A., "Improving Hospital Bed Utilisation through Simulation and Optimisation: With Application to a $40 \%$ Increase in Patient Volume in a Norwegian General Hospital”, International Journal of Medical Informatics, Volume 82, No. 2, pp. 80-89, 2013.

[17] Abo-Hamad, W., and Arisha, A., "Simulation-Based Framework to Improve Patient Experience in an Emergency Department", European Journal of Operational Research, Volume 224, No. 1, pp. 154-166, 2013.

[18] Branas, C.C., Catherine, S.W., Williams, J., Margolis, G., and Carr, B.G., "Simulating Changes to Emergency Care Resources to Compare System Effectiveness", Journal of Clinical Epidemiology, Volume 66, No. 8, Supplement, pp. S57-S64, 2013.

[19] Paul, J.A., and Lin, L., "Models for Improving Patient Throughput and Waiting at Hospital Emergency Departments", The Journal of Emergency Medicine, Volume 43, No. 6, pp. 1119-1126, 2012.

[20] Pakistan, C.O., "District Glance", Peshwar, Pakistan, 1998.

[21] Rescue1122kpk,

[22] Alsallouma, O.I., and Rand, G.K., "Extensions to Emergency Vehicle Location Models", Computers \& Operations Research, Volume 33, pp. 2725-2743, 2006. 